\title{
Caracterização e extração de compostos voláteis de resíduos do processamento de maracujá (Passiflora edulis Sims f. flavicarpa Degener)
}

\author{
Characterization and extraction of volatile compounds from passion fruit \\ (Passiflora edulis Sims f. flavicarpa Degener) processing waste
}

\begin{abstract}
Lília Calheiros de Oliveira ${ }^{I^{*}}$ João Antônio Belmino dos Santos ${ }^{\mathrm{I}}$ Narendra Narain ${ }^{\mathrm{I}}$ Anderson dos Santos Fontes ${ }^{\mathrm{I}}$ Regina Santiago Silva Campos $^{\mathrm{I}}$ Taciana Lima de Souza $^{\mathrm{I}}$
\end{abstract}

\section{RESUMO}

\begin{abstract}
Este estudo objetivou extrair e identificar compostos voláteis presentes nos resíduos de processo de maracujá. Obtiveram-se destilados a partir de resíduos de maracujá através das técnicas de hidrodestilação simples e hidrodestilação com arraste de gás nitrogênio. Os compostos voláteis presentes nos destilados foram capturados por microextração em fase sólida, empregando-se fibra Carboxen/DVB/DMS, e identificados por cromatografia gasosa acoplada com espectrômetro de massa, usando a coluna capilar de sílica fundida CP WAX 52. Foram identificados trinta e um compostos voláteis no extrato obtido pela técnica de hidrodestilação simples, sendo os principais compostos: neral (26,19\%), cinamato de metila (18,52\%), linalol (16,82\%), 1-undecanol (5,60\%), cis-óxido de linalol $(4,41 \%)$, benzaldeído (3,92\%) e 1-hexanol (3,48\%). Para a hidrodestilação com arraste de gás nitrogênio, trinta compostos foram identificados, sendo que, em maior porcentagem de área, destacaram-se: cinamato de metila $(30,41 \%)$, neral $(24,46 \%)$, $\beta$-ionona $(13,81 \%)$, linalol $(4,0 \%)$ e acido butanoico $(2,19 \%)$. o presente estudo revelou que os resíduos de maracujá apresentam compostos voláteis que podem ser extraídos na forma de aromas, apresentando potencial para gerar essências naturais com valor agregado.
\end{abstract}

Palavras-chave: resíduos agroindustriais, destilação, cromatografia gasosa.

\section{ABSTRACT}

The aim of this study was to extract and identify volatile compounds from passion fruit residues generated during processing. Distillates of passion fruit residues were obtained from the techniques of simple hydrodistillation and hydrodistillation by passing nitrogen gas. The volatile compounds present in the distillates were captured by solid phase microextraction with Carboxen/DVB/DMS fiber. The volatile compounds were indentified by gas chromatography with mass spectrometry using a fused sillica capillary column with a CP WAX 52 stationary phase. Thirty one compounds were indentified by simple hydrodistillation technique. The main compounds were: neral (26.19\%), methyl cinnamate (18.52\%), linalool (16.82\%), 1-undecanol (5.60\%), cis-linalool oxide $(4.41 \%)$, benzaldehyde $(3.92 \%)$ and 1-hexanol (3.48\%). For the hydrodistillation by passing nitrogen gas, thirty compounds were identified and the ones which presented higher area percentage were: methyl cinnamate (30.41\%), neral (24.46\%), $\beta$-ionone (13.81\%), linalool (4.0\%) and butanoic acid $(2.19 \%)$. The present study revealed that passion fruit waste contained volatile compounds that could be extracted as aromas products, presenting potential for the production of value-added natural essences.

Key words: agro-industrial residues, distillation, gas chromatography.

\section{INTRODUÇÃO}

O Brasil é o principal produtor e consumidor mundial de maracujá. Conforme censo do Instituto Brasileiro de Geografia e Estatística (IBGE, 2011), o país produziu 684 mil toneladas de maracujá em 2008 e a região Nordeste deteve $68 \%$ dessa produção, sendo a Bahia o destaque com produção de 275 mil toneladas (EMBRAPA, 2008).

A produção brasileira de maracujá possui basicamente dois destinos: o mercado de fruta in natura, distribuído pelo mercado atacadista, e a indústria de extração de polpa e fabricação de suco

\footnotetext{
'Laboratório de Flavor e Análises Cromatográficas (LAF), Universidade Federal de Sergipe (UFS), 49100-000, São Cristóvão, SE,
}

Brasil. E-mail: liliacalheiros@ gmail.com. *Autor para correspondência. 
(TEIXEIRA, 2005). Ambos, a fruta in natura e o suco, são produtos muito apreciados em função de suas características sensoriais (MACORIS et al., 2011).

Existem consideráveis perdas de produtos agrícolas nas diversas etapas da cadeia produtiva, desde a produção no campo até o momento de consumo, passando pela elevada geração de resíduos no processamento agroindustrial de produtos animais e vegetais. Estima-se que o aproveitamento das matérias-primas vegetais não ultrapasse $85 \%$ e que os resíduos gerados possam chegar até $30 \%$. Além da preservação ambiental, o aproveitamento desses resíduos abrange questões econômicas e sociais (MATSUURA, 2005).

As cascas e as sementes de maracujá, provenientes do processo de corte e extração da fruta para obtenção do suco, são, ainda, em grande parte, descartadas e representam cerca de $40 \%$ do peso total do fruto. Como este descarte representa inúmeras toneladas, agregar valor a esses subprodutos é de interesse econômico, científico e tecnológico (FERRARI et al., 2004; CARVALHO et al., 2005). Estudos anteriores têm reportado a aplicação de resíduo de maracujá para extração de óleo a partir das sementes (FERRARI et al., 2004); alimentação animal (CARVALHO et al., 2005; NEIVAet al., 2006); produção de novos produtos, como, barras de cereais (SILVA et al., 2009), biscoitos enriquecidos com a farinha da casca de maracujá (ISHIMOTO et al., 2007; ABUD \& NARAIN, 2009) e doce da casca de maracujá (OLIVEIRA et al., 2002).

Muitos compostos voláteis foram identificados no maracujá e em seus derivados (NARAIN et al., 2004; VIEIRA, 2006; CIAMPONE, 2007; PONTES et al., 2009; MACORIS et al., 2011); no entanto, não existem estudos que reportem a quantificação e identificação de compostos voláteis nos resíduos de maracujá.

O objetivo deste trabalho foi extrair compostos voláteis a partir de resíduos de maracujá através das técnicas de hidrodestilação simples e hidrodestilação com arraste de gás nitrogênio, ambas combinadas à microextração em fase sólida (SPME) e identificá-los por cromatografia gasosa acoplada a detector de espectrometria de massa (GC-MS).

\section{MATERIAL E MÉTODOS}

Os resíduos de maracujá foram fornecidos por uma indústria de sucos concentrados e congelados localizada no município de Estância, Sergipe, Brasil. A composição consistia de fibra residual obtida durante o despolpamento das frutas em equipamento com tela de filtração de abertura de 1,2mm. As amostras foram diretamente acondicionadas em sacos de polietileno de baixa densidade e armazenadas em freezer à temperatura de $-18^{\circ} \mathrm{C}$. Para a extração dos compostos voláteis, as amostras foram descongeladas à temperatura ambiente e diluídas com água destilada na proporção de 3:1.

\section{Hidrodestilação simples}

Os compostos voláteis dos resíduos de maracujá foram extraídos em um destilador de bancada em triplicata. Pesaram-se 50g dos resíduos diluídos em água (3:1) e transferiram-se para um balão volumétrico de fundo chato de $500 \mathrm{~mL}$, o qual foi acoplado a um condensador e aquecido em uma manta com regulagem de temperatura. Para a obtenção dos destilados, foram aplicadas as condições: tempo de extração $(5,10,15$ e 30 minutos) e temperatura $\left(70,80\right.$ e $\left.90^{\circ} \mathrm{C}\right)$. As amostras foram armazenadas em vidros escuros tipo âmbar e congeladas em um freezer à temperatura de $-18^{\circ} \mathrm{C}$ até o momento da captura dos voláteis pela técnica SPME.

Hidrodestilação com arraste de gás nitrogênio

Para a extração dos compostos voláteis com arraste de gás nitrogênio, foram pesados $200 \mathrm{~g}$ do resíduo previamente diluído em água (3:1) e transferidos para balão de duas vias de $1000 \mathrm{~mL}$, nas quais foram acoplados um condensador e um borbulhador de gás que permitia a passagem de gás nitrogênio de alta pureza. O balão foi aquecido em uma manta com regulagem de temperatura. A temperatura usada para esta extração foi de $60^{\circ} \mathrm{C}$ e a pressão do gás de $0,4 \mathrm{kgf}$ $\mathrm{cm}^{-2}$, sendo os tempos de extração de $5,10,15$ e 30 minutos. Os destilados obtidos foram armazenados em vidros escuros tipo âmbar e congelados em um freezer à temperatura de $-18^{\circ} \mathrm{C}$ até etapa de captura dos voláteis pelo método SPME.

\section{Microextração em fase sólida (SPME)}

Os compostos voláteis presentes nos destilados obtidos por ambas as técnicas de hidrodestilação foram capturados pelo método de microextração em fase sólida. Para a realização deste procedimento, utilizaram-se $5 \mathrm{~mL}$ de cada destilado em vial de vidro de $40 \mathrm{~mL}$ com tampa vasada e septo de teflon, contendo barra de ímã para facilitar a homogeneização. O vial de $40 \mathrm{~mL}$ foi aquecido em banho-maria a $40^{\circ} \mathrm{C}$ em agitador-aquecedor. Após tempo de equilíbrio de 10 minutos, a fibra SPME Carboxen/DVB/PDMS foi exposta por 30 minutos. Em seguida, ela foi injetada no cromatógrafo gasoso acoplado ao espectrômetro de massa. 
Cromatografia gasosa e espectrometria de massa (GC-MS)

A separação dos compostos da fração volátil ocorreu em coluna capilar (CP WAX 52 de polietileno glicol, marca Varian; $30 \mathrm{~m}$ de comprimento $\mathrm{x}$ $0,25 \mathrm{~mm}$ i.d $\times 0,25 \mu \mathrm{m}$ de espessura de filme), em temperatura programada, iniciando a $30^{\circ} \mathrm{C}$ (3 minutos), com rampa de $2^{\circ} \mathrm{C} \mathrm{min}^{-1}$ até $120^{\circ} \mathrm{C}$ (1 minuto), seguido de rampa de $2^{\circ} \mathrm{C} \mathrm{min}^{-1}$ até $250^{\circ} \mathrm{C}$, sendo o tempo total da corrida de 114 minutos, modo splitless. Gás hélio foi utilizado como gás de arraste. A temperatura da linha de transferência GC-MS foi de $170^{\circ} \mathrm{C}$. O espectrômetro de massa foi operado no modo de ionização de elétrons com uma energia elétrica de $70 \mathrm{eV}$ e uma fonte de íons com temperatura de $250^{\circ} \mathrm{C}$. A leitura da massa ocorreu entre $50 \mathrm{e} 1000 \mathrm{~m} \mathrm{z}^{-1}$.

\section{Identificação dos compostos voláteis}

Os cromatogramas de íon total obtidos foram analisados com a estação de trabalho EM Data Review (marca Varian). A identificação dos compostos foi feita com base na similaridade entre os espectros de massas do analito comparado aos dados de espectros de massas da biblioteca NIST (National Institute of Standards and Technology), usando como ferramenta auxiliar os Índices de Retenção Linear (IRL) de cada analito obtido nas mesmas condições de análise das amostras, a partir de uma série homóloga de alcanos de $\mathrm{C}_{8}-\mathrm{C}_{30}$. A confirmação dos compostos foi realizada pela consulta dos dados dos espectros ou índice de retenção linear registrados na literatura.

\section{RESULTADOS E DISCUSSÃO}

$\mathrm{Na}$ figura 1, está apresentado o cromatograma do resíduo de maracujá tratado por hidrodestilação simples à temperatura de $70^{\circ} \mathrm{Ce}$ tempo de extração de 15 minutos e voláteis capturados por SPME e detectados por GC-MS. As condições de extração para a hidrodestilação simples foram escolhidas em função de resultado prévio de análise cromatográfica, uma vez que, para temperatura de $70^{\circ} \mathrm{C}$ por tempo de 30 minutos e para todas as outras condições de temperaturas testadas, ou seja, a $80^{\circ} \mathrm{C}$ e $90^{\circ} \mathrm{C}$, houve presença de compostos característicos de degradação da amostra. Para as condições de extração a $70^{\circ} \mathrm{C}$, por tempos de 5 e 10 minutos, apesar de não haver degradação, os picos obtidos foram muito menores, quando comparados à condição de extração de $70^{\circ} \mathrm{C}$ por 15 minutos.

Este cromatograma apresenta trinta e um compostos voláteis detectados na cromatografia gasosa. Destes, vinte e quatro foram identificados através do índice de retenção e espectro de massas e sete foram identificados por tentativa. Os picos observados na figura 1 encontram-se listados na tabela 1. O resíduo de maracujá apresentou em sua composição $29 \%$ de alcoois, sendo esta a principal classe de compostos identificados. Os ésteres foram a segunda maior classe (20\%), seguidos de outros compostos (19\%), aldeídos (16\%), ácidos (10\%) e cetonas (6\%).

$\mathrm{Na}$ tabela 1, estão apresentados os compostos voláteis identificados no resíduo de

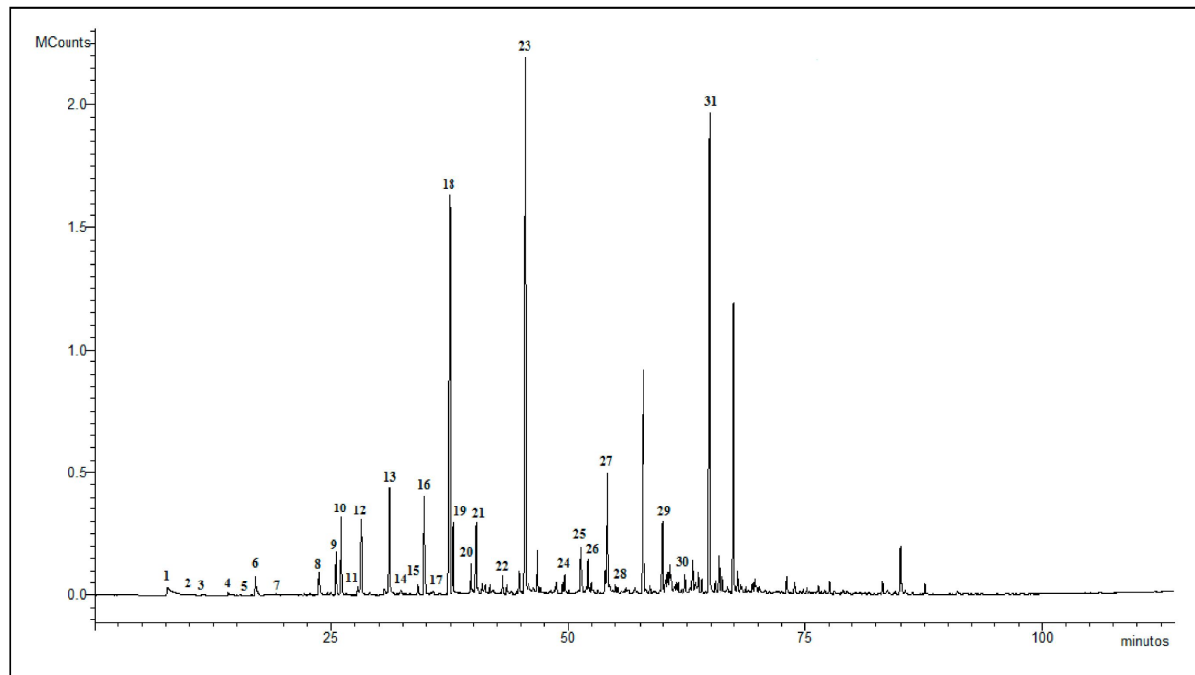

Figura 1 - Cromatograma obtido pela captura de compostos voláteis por microextração em fase sólida do destilado do resíduo de maracujá tratado por hidrodestilação simples.

Ciência Rural, v.42, n.12, dez, 2012. 
Tabela 1 - Compostos voláteis capturados por SPME dos destilados de resíduos de maracujá tratados por hidrodestilação simples.

\begin{tabular}{|c|c|c|c|c|c|c|c|c|}
\hline \multirow{2}{*}{$\begin{array}{l}\text { Pico } \\
\text { Fig. } 1\end{array}$} & \multirow[b]{2}{*}{ Composto } & \multirow[b]{2}{*}{ Área (\%) } & \multirow[b]{2}{*}{ DPR } & \multirow[b]{2}{*}{ IR } & \multicolumn{4}{|c|}{---IR Literatura--- } \\
\hline & & & & & A & B & $\mathrm{C}$ & $\mathrm{D}$ \\
\hline 1 & Dissulfeto de dimetila & 0,55 & 9,62 & 1073 & - & 1075 & 1075 & 1064 \\
\hline 2 & 1-Hexanal & 0,02 & 12,07 & 1089 & 1065 & 1084 & 1080 & 1099 \\
\hline 3 & 2-Pentanol & 0,08 & 10,45 & 1113 & 1113 & 1091 & 1122 & - \\
\hline 4 & Mirceno & 0,09 & 6,82 & 1161 & 1148 & 1156 & 1170 & 1172 \\
\hline 5 & Limoneno & 0,04 & 12,63 & 1181 & 1188 & 1206 & 1195 & 1205 \\
\hline 6 & Dissulfeto de dietila & 0,86 & 5,63 & 1208 & - & - & 1210 & 1192 \\
\hline 7 & 1-Pentanol & 0,04 & 9,66 & 1243 & 1222 & - & 1248 & 1244 \\
\hline 8 & 2-Heptanol & 0,93 & 3,15 & 1314 & 1323 & 1284 & 1322 & - \\
\hline 9 & 2-Nonanona & 1,49 & 6,42 & 1342 & 1372 & - & 1350 & - \\
\hline 10 & Éter hexílico & 2,47 & 1,14 & 1352 & - & 1349 & - & - \\
\hline 11 & (Z)-3 Hexen-1-ol & 0,26 & 15,23 & 1378 & 1362 & - & 1381 & 1399 \\
\hline 12 & 1-Hexanol & 3,48 & 7,41 & 1384 & 1331 & 1316 & 1356 & 1364 \\
\hline 13 & cis-Óxido de linalol & 4,41 & 12,63 & 1432 & 1426 & 1423 & - & 1448 \\
\hline 14 & 1-Heptanol & 0,21 & 9,28 & 1452 & 1400 & 1419 & 1459 & - \\
\hline 15 & Furfural & 0,04 & 14,31 & 1448 & 1426 & 1449 & 1461 & 1410 \\
\hline 16 & Benzaldeído & 3,92 & 2,56 & 1492 & 1492 & 1502 & 1527 & 1555 \\
\hline 17 & Hexanoato de pentila & 0,13 & 11,39 & 1507 & 1498 & - & 1505 & - \\
\hline 18 & Linalol & 16,82 & 3,27 & 1537 & 1519 & 1506 & 1542 & 1557 \\
\hline 19 & 1-Octanol & 2,64 & 11,81 & 1545 & 1535 & 1519 & 1558 & 1575 \\
\hline 20 & 5-Metilfurfural & 0,16 & 15,33 & 1580 & - & 1563 & 1580 & - \\
\hline 21 & Ácido butanoico & 2,82 & 5,96 & 1586 & 1588 & - & - & 1638 \\
\hline 22 & (Z)-3 Hexanoato de hexenila & 0,48 & 10,30 & 1634 & 1626 & 1654 & 1635 & - \\
\hline 23 & Neral & 26,19 & 2,50 & 1677 & 1657 & 1680 & - & 1709 \\
\hline 24 & Acetato de benzila & 0,34 & 8,54 & 1736 & 1648 & 1697 & 1720 & - \\
\hline 25 & Acetato de feniletila & 2,13 & 6,48 & 1784 & 1780 & 1785 & - & - \\
\hline 26 & Ácido hexanoico & 1,15 & 0,21 & 1798 & 1797 & - & - & - \\
\hline 27 & 1-Undecanol & 5,60 & 4,60 & 1837 & 1827 & 1822 & - & - \\
\hline 28 & Álcool benzílico & 0,18 & 11,93 & 1857 & 1837 & - & 1884 & 1893 \\
\hline 29 & $\beta$-Ionona & 2,71 & 0,63 & 1950 & 1905 & 1918 & 1952 & 1984 \\
\hline 30 & Ácido octanoico & 1,24 & 5,26 & 2014 & 2008 & - & - & 2047 \\
\hline 31 & Cinamato de metila & 18,52 & 2,47 & 2051 & 2050 & 2051 & - & - \\
\hline
\end{tabular}

DPR - Desvio padrão relativo (DP média-1 x 100) de três injeções;

IR - Índice de retenção;

A - KONDJOYAN \& BERDAGUÉ (1996);

B - JENNINGS \& SHIBAMOTO (1980);

C - NARAIN et al. (2004);

D - CREC database (2011)

maracujá extraídos pela técnica de hidrodestilação simples. Os principais componentes foram neral $(26,19 \%)$, cinamato de metila $(18,52 \%)$, linalol $(16,82 \%)$, 1-undecanol $(5,60 \%)$, cis-óxido de linalol $(4,41 \%)$, benzaldeído (3,92\%) e 1-hexanol (3,48\%).

O cromatograma do resíduo de maracujá tratado por hidrodestilação com arraste de gás nitrogênio, sob condições de temperatura de extração de $60^{\circ} \mathrm{C}$, pressão do gás de $0,4 \mathrm{kgf} \mathrm{cm}^{-2} \mathrm{e}$ intervalo de tempo de 30 minutos está apresentado na figura 2. Os tempos de 5,10 e 15 minutos apresentaram picos muito menores, quando comparados ao cromatograma obtido para o tempo de 30 minutos, dessa forma, este foi eleito o melhor tempo de extração para aplicação dessa técnica. A vantagem da hidrodestilação com arraste de gás nitrogênio foi a utilização de temperatura mais baixa, quando comparada à hidrodestilação simples, o que evitou a degradação da amostra por caramelização.

Para esta técnica de extração, trinta compostos voláteis foram detectados por GC-MS. Destes, vinte e 


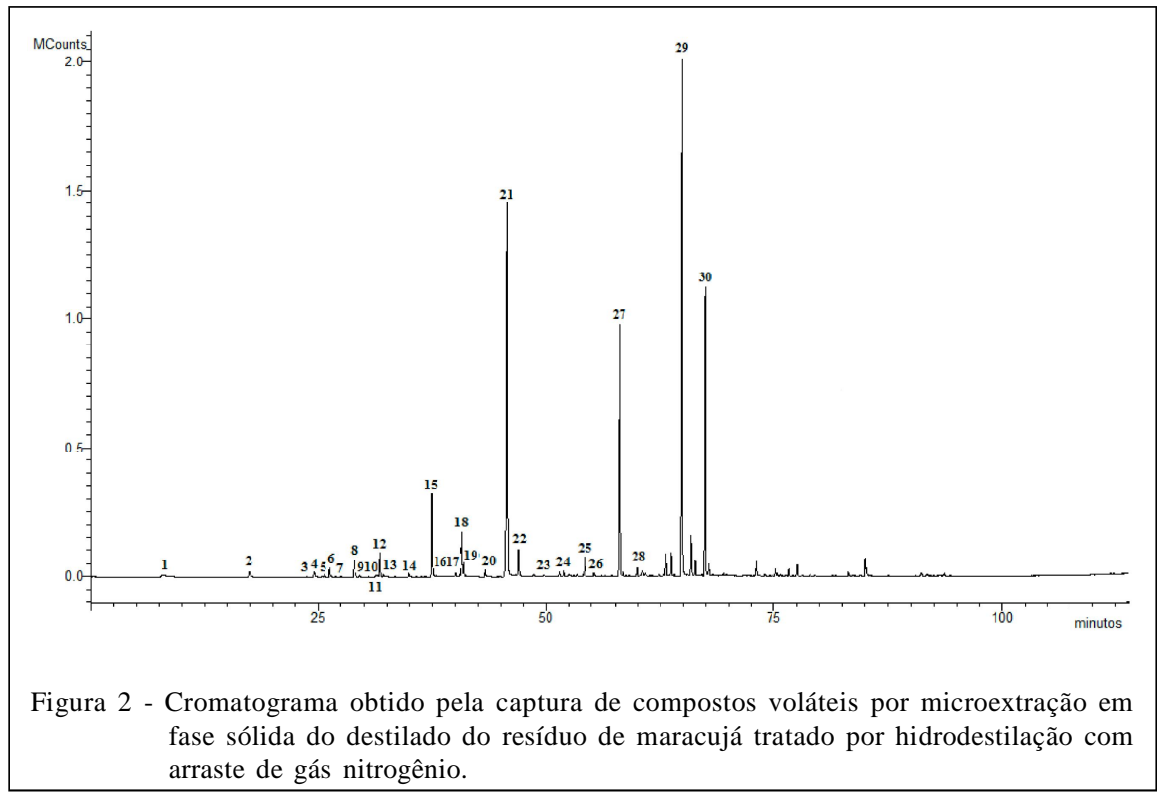

dois foram positivamente identificados através do índice de retenção e espectro de massas e oito foram identificados por tentativa. Os picos observados na figura 2 encontram-se listados também na tabela 2 . $\mathrm{O}$ resíduo de maracujá apresentou em sua composição $30 \%$ de ésteres, sendo esta a principal classe de compostos identificados. Os alcoois foram a segunda maior classe (27\%), seguidos de aldeídos (13\%) e outros compostos (13\%), ácidos (10\%) e cetonas $(7 \%)$.

$\mathrm{Na}$ tabela 2, estão apresentados os compostos identificados no resíduo de maracujá, extraídos pela técnica de hidrodestilação com arraste de gás nitrogênio, capturados por SPME e detectados por cromatografia gasosa de alta resolução. Os principais componentes foram cinamato de metila $(30,41 \%)$, neral $(24,46 \%)$, eugenol $(14,61 \%), \beta$-ionona $(13,81 \%)$, linalol $(4,0 \%)$ e acido butanoico $(2,19 \%)$.

Para os dois processos de destilação aplicados neste estudo, ou seja, a hidrodestilação simples e a hidrodestilação com arraste de gás nitrogênio, dois componentes foram comuns e apresentaram elevada porcentagem de área para ambos os cromatogramas: o neral $(26,19 \%$ e $24,46 \%$; respectivamente) e o cinamato de metila $(18,52 \%$ e $30,41 \%$; respectivamente). CIAMPONE (2007) também identificou esses dois compostos no isolado de fase aquosa (water phase) de maracujá.

Os dois cromatogramas apresentaram grande quantidade de ésteres, compostos voláteis que influenciam diretamente no aroma de vários produtos por serem responsáveis por notas aromáticas frutais. Os alcoois também se destacaram no resíduo de maracujá e, de acordo com diversos autores, eles são compostos comuns presentes nesta fruta (WERKHOFF et al., 1998; NARAIN et al., 2004; CIAMPONE, 2007; FREITAS, 2007; PONTES etal. 2009).

A presença dos aldeídos 1-hexanal, furfural, benzaldeído e 5-metilfurfural e dos alcoois 2-pentanol, 1-pentanol, 2-heptanol, 1-heptanol e 1-octanol foi reportada em estudo de caracterização de compostos voláteis em polpa de maracujá, através da técnica de headspace dinâmico e cromatografia gasosa com coluna capilar de sílica fundida, recoberta com filme de polietileno glicol, similar à utilizada neste trabalho (NARAIN et al., 2004). Os compostos furfural e 5metilfurfural, identificados no resíduo de maracujá, podem ter sido formados pela reação do rearranjo Amadori, envolvendo primeiramente as carbonilas, usualmente dos açúcares redutores e dos grupos aminos livres (NARAIN et al., 2004).

CIAMPONE (2007) reportou a presença dos compostos cis-óxido de linalol, ácido hexanoico, neral, acetato de benzila e ácido octanoico na caracterização de water phase de maracujá amarelo. Em estudo sobre avaliação da estabilidade de suco de maracujá envasados em diferentes embalagens, FREITAS (2007) observou a presença dos seguintes compostos majoritários: propanoato de etila, hexanol, hexanoato de etila e (Z)-3-hexanol.

Os compostos butanoato de hexila, acetato de hexila, 1-octanol, hexanoato de butila, furfural, 1hexanol, cis-óxido de linalol, benzaldeído, álcool benzílico, ácido hexanoico, 5-metilfurfural, (Z)-3- 
Tabela 2 - Compostos voláteis capturados por SPME dos destilados de resíduos de maracujá tratados por hidrodestilação com arraste de gás nitrogênio.

\begin{tabular}{|c|c|c|c|c|c|c|c|c|}
\hline \multirow{2}{*}{$\begin{array}{l}\text { Pico } \\
\text { Fig. } 2\end{array}$} & \multirow[b]{2}{*}{ Composto } & \multirow[b]{2}{*}{ Área (\%) } & \multirow[b]{2}{*}{ DPR } & \multirow[b]{2}{*}{ IR } & \multicolumn{4}{|c|}{ 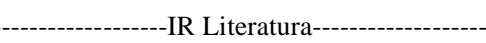 } \\
\hline & & & & & A & B & $\mathrm{C}$ & $\mathrm{D}$ \\
\hline 1 & Dissulfeto de dimetila & 0,20 & 11,87 & 1074 & - & 1075 & 1075 & 1064 \\
\hline 2 & Dissulfeto de dietila & 0,50 & 6,44 & 1215 & - & - & 1210 & 1192 \\
\hline 3 & Acetato de hexila & 0,03 & 11,05 & 1314 & 1307 & - & - & - \\
\hline 4 & 2-Heptanol & 0,43 & 1,49 & 1327 & 1323 & 1284 & 1322 & - \\
\hline 5 & 1-Hexanol & 0,16 & 9,26 & 1345 & 1331 & 1316 & 1356 & 1364 \\
\hline 6 & (E)-3 Hexen-1-ol & 0,54 & 13,21 & 1355 & 1357 & - & - & - \\
\hline 7 & 2-Nonanona & 0,03 & 8,52 & 1365 & 1372 & - & 1350 & - \\
\hline 8 & 1-Heptanol & 0,98 & 4,87 & 1396 & 1400 & 1419 & 1459 & - \\
\hline 9 & Hexanoato de butila & 0,11 & 13,31 & 1404 & 1404 & - & - & - \\
\hline 10 & Butanoato de hexila & 0,02 & 14,42 & 1422 & 1420 & - & - & - \\
\hline 11 & cis-Óxido de linalol & 0,18 & 9,65 & 1437 & 1426 & 1423 & - & 1448 \\
\hline 12 & trans-Óxido de linalol & 1,18 & 0,54 & 1442 & 1440 & - & - & - \\
\hline 13 & Furfural & 0,16 & 14,54 & 1448 & 1426 & 1449 & 1461 & 1410 \\
\hline 14 & Benzaldeído & 0,18 & 13,62 & 1495 & 1492 & 1502 & 1527 & 1555 \\
\hline 15 & Linalol & 4,00 & 2,87 & 1537 & 1519 & 1506 & 1542 & 1557 \\
\hline 16 & 1-Octanol & 0,05 & 15,32 & 1546 & 1535 & 1519 & 1558 & 1575 \\
\hline 17 & 5-Metilfurfural & 0,26 & 8,25 & 1582 & - & 1563 & 1580 & - \\
\hline 18 & Ácido butanoico & 2,19 & 6,16 & 1593 & 1588 & - & - & 1638 \\
\hline 19 & Hexanoato de hexila & 0,85 & 3,24 & 1596 & 1599 & - & - & - \\
\hline 20 & (Z)-3 Hexanoato de hexenila & 0,34 & 9,18 & 1638 & 1626 & 1654 & 1635 & - \\
\hline 21 & Neral & 24,46 & 3,80 & 1680 & 1657 & 1680 & - & 1709 \\
\hline 22 & Acetato de benzila & 1,42 & 5,21 & 1704 & 1648 & 1697 & 1720 & - \\
\hline 23 & Acetato de feniletila & 0,23 & 8,55 & 1786 & 1780 & 1785 & - & - \\
\hline 24 & Ácido hexanoico & 0,25 & 8,14 & 1795 & 1797 & - & - & - \\
\hline 25 & 1-Undecanol & 0,95 & 4,68 & 1837 & 1827 & 1822 & - & - \\
\hline 26 & Álcool benzílico & 0,21 & 14,85 & 1858 & 1837 & - & 1884 & 1893 \\
\hline 27 & $\beta$-Ionona & 13,81 & 2,28 & 1910 & 1905 & 1918 & 1952 & 1984 \\
\hline 28 & Ácido octanoico & 1,24 & 5,73 & 2014 & 2008 & - & - & 2047 \\
\hline 29 & Cinamato de metila & 30,41 & 1,45 & 2051 & 2050 & 2051 & - & - \\
\hline 30 & Eugenol & 14,61 & 3,29 & 2106 & 2115 & - & - & - \\
\hline
\end{tabular}

DPR - Desvio padrão relativo (DP média-1 x 100) de três injeções;

IR - Índice de retenção;

A - KONDJOYAN \& BERDAGUÉ (1996);

B - JENNINGS \& SHIBAMOTO (1980);

C - NARAIN et al. (2004);

D - CREC database (2011).

hexanoato de hexenila, 2-heptanol, (E)-3-hexen-1-ol, hexanoato de hexila, 1-heptanol, trans-óxido de linalol, ácido octanoico, acetato de benzila, ácido butanoico, linalol, B-ionona, eugenol, neral e cinamato de metila também foram reportados por WERKHOFF et al. (1998), que extraiu os voláteis da polpa de maracujá através de headspace a vácuo, seguido de extração líquido-líquido com solvente metil tércio-butil éter.

Dentre os compostos voláteis existentes em aromas de maracujá e que apresentam importância odorífera de acordo com a literatura científica (CIAMPONE, 2007), destacam-se: neral, cinamato de metila e linalol. Esses compostos também foram identificados nos resíduos dessa fruta, o que indica que estes apresentam potencial para obtenção de essências altamente aromáticas que podem ser reincorporadas a produtos derivados, como o suco concentrado de maracujá, de forma a contribuir, tanto para elevar a qualidade sensorial, quanto para aumentar a sua competitividade no mercado externo. 


\section{CONCLUSÃO}

O presente estudo revelou que o resíduo de maracujá apresenta razoável quantidade de compostos voláteis similares aos encontrados na fruta in natura. Ésteres e alcoois foram as classes de compostos mais abundantes, com destaque para neral, cinamato de metila e linalol, os quais apresentam grande importância odorífera. Os resultados obtidos indicam que os resíduos de maracujá apresentam viabilidade para a produção de essências aromáticas, que podem contribuir para aumentar a qualidade sensorial de produtos derivados de maracujá.

\section{AGRADECIMENTOS}

Ao Instituto Nacional de Ciência e Tecnologia de Frutos Tropicais, pelo apoio financeiro.

\section{REFERÊNCIAS}

ABUD, A.K.S.; NARAIN, N. Incorporação da farinha de resíduo do processamento de polpa de fruta em biscoitos: uma alternativa de combate ao desperdício. Brazilian Journal of Food Technology, v.12, n.4, p.257-265, 2009. Disponível em: <http:/ /bj.ital.sp.gov.br/artigos/html/busca/PDF/v12n4389a.pdf>. Acesso em: 04 mar. 2011. doi: 10.4260/BJFT2009800900020.

CARVALHO, A.V. et al. Aproveitamento do mesocarpo do maracujá na fabricação de produtos flavorizados. Comunicado Técnico 147, Embrapa, 2005. Acesso em: 05 maio, 2011. Online. Disponível em: <http://www.infoteca.cnptiaembrapa.br/bitstream/ doc/389639/1/com.tec.147.pdf $>$.

CIAMPONE, S. Perfil de voláteis em water phase de maracujá amarelo (Passiflora edulis $f$. Flavicarpa degener) e avaliação de seu potencial para a produção de essência natural. 2007. 117f. Tese (Doutorado em Alimentos e Nutrição) - Faculdade de Engenharia de Alimentos, Universidade Estadual de Campinas, SP.

CREC Database. Base de dados do Centro de Educação e Pesquisa de Citros (Citrus Research and Education Center CREC), Universidade da Flórida, 2011. Acesso em: 04 jul. 2011. Online. Disponível em: <http://www.crec.ifas.ufl.edu/ crec_websites/Rouseff/Website $2002 /$ Subpages/ database_g_Frameset.shtml>.

EMBRAPA. Produção integrada de abacaxi na Bahia, Paraíba e Pernambuco. Centro Nacional de Pesquisa de Mandioca e Fruticultura Tropical, 2008. Acesso em: 17 maio, 2011. Online. Disponível em: <http://www.cnpmf.embrapa.br/ pic_bahia/Projeto_Producao_Integrada_Abacaxi.pdf $>$.

FERRARI, R.A. et al. Caracterização de subprodutos da industrialização do maracujá - aproveitamento das sementes. Revista Brasileira de Fruticultura, v.26, n.1, p.101-102, 2004. Disponível em: <http://www.scielo.br/pdf/rbf/v26n1/ a27v26n1.pdf >. Acesso em: 28 mar. 2011. doi: 10.1590/ S0100-29452004000100027.

FREITAS, V.M. Estudos das alterações do suco de maracujá integral em embalagem do tipo PET e vidro. 2007. $76 \mathrm{f}$.
Dissertação (Mestrado em Tecnologia de Alimentos) Departamento de Tecnologia de Alimentos, Universidade Federal do Ceará, CE.

IBGE (Instituto Brasileiro de Geografia de Estatística). Produção Agrícola. Acesso em: 26 mar. 2011. Online. Disponível em: <http://www.ibge.gov.br〉.

ISHIMOTO, F.Y. et al. Aproveitamento alternativo da casca do maracujá-amarelo (Passiflora edulis f. var flavicarpa Deg.) para produção de biscoitos. Ciências Exatas e Naturais, v.9, n.2, p.279-292, 2007. Disponível em: <http://www.scielo.br/ pdf/cta/v22n3/v22n3a11.pdf >. Acesso em: 02 abr. 2011.

JENNINGS, W.; SHIBAMOTO, T. Qualitative analysis of flavor and fragrance volatiles by glass capillary gas chromatography. New York: Academic, 1980. 472p.

KONDJOYAN, N.; BERDAGUÉ, J.L. A compilation of relative retention indices for the analysis of aromatic compounds. Clermont-Ferrand, France: Laboratoire Flaveur, 1996. 112p.

MACORIS, M.S. et al. Volatile compounds from organic and conventional passion fruit (Passiflora edulis f. var flavicarpa Deg.) pulp. Ciência e Tecnologia de Alimentos, v.31, n.2, p.430-435, 2011. Disponível em: <http://www.scielo.br/pdf/ cta/v31n2/v31n2a23.pdf >. Acesso em: 14 jul. 2011. doi: 10.1590/S0101-20612011000200023.

MATSUURA, F.C.A.U. Estudo do albedo de maracujá e de seu aproveitamento em barra de cereais. 2005. 138f. Tese (Doutorado em Engenharia de Alimentos) - Faculdade de Engenharia de Alimentos, Universidade Estadual de Campinas, SP.

NARAIN, N. et al. Compostos voláteis dos frutos de maracujá (Passiflora edulis forma Flavicarpa) e de cajá (Spondias mombin L.) obtidos pela técnica de headspace dinâmico. Ciência e Tecnologia de Alimentos, v.24, n.2, p.212-216, 2004. Disponível em: <http://www.scielo.br/pdf/cta/v24n2/ v24n2a09.pdf >. Acesso em: 05 mar. 2011. doi: 10.1590/ S0101-20612004000200009.

NEIVA, J.N.M. et al. Valor nutritivo de silagens de capimelefante enriquecidas com subproduto do processamento do maracujá. Revista Brasileira de Zootecnia, v.35, n.4, p.1845-1851, 2006. Disponível em: <http://www.scielo.br/pdf/ rbz/v35n4s0/a36v354s.pdf>. Acesso em: 23 abr. 2011. doi: 10.1590/S1516-35982006000600036.

OLIVEIRA, L.F. et al. Aproveitamento alternativo da casca do maracujá-amarelo (Passiflora edulis f. Flavicarpa) para produção de doce em calda. Ciência e Tecnologia de Alimentos, v.22, n.3, p.259-262, 2002. Disponível em: <http://www.unicentro.br/ editora/revistas/recen/v9n2/279-292_art08.pdf >. Acesso em: 20 jun. 2011. doi: 10.1590/S0101-20612002000300011.

PONTES, M. et al. Headspace solid-phase microextractiongas chromatography-quadrupole mass spectrometric methodology for the establishment of the volatile composition of Passiflora fruit species. Microchemical Journal., v.93, p.1-11, 2009. Disponível em: <http://www.sciencedirect.com/ science/article/pii/S0026265X09000319>. Acesso em: 08 jun. 2011. doi: http://dx.doi.org/10.1016/j.microc.2009.03.010.

SILVA, I.Q. et al. Obtenção de barra de cereais adicionada do resíduo industrial de maracujá. Alimentos e Nutrição, v.20, 
n.2, p.321-329, 2009. Disponível em: <http:// servbib.fcfar.unesp.br/seer/index.php/alimentos/article/viewFile/ 1064/815>. Acesso em: 02 abr. 2011.

TEIXEIRA, S.T. Mercado exportador - análise para a cultura do maracujá, 2005. Acesso em: 24 jun. 2010. Online. Disponível em: <http://www.todafruta.com.br/todafruta/ mostra_conteudo.asp?conteudo $=8543>$.

VEIRA, M.A.R. Caracterização dos ácidos graxos das sementes e compostos voláteis dos frutos de espécies do gênero Passiflora. 2006. 71f. Dissertação (Mestrado em Agronomia) - Faculdade de Ciências Agronômicas, Universidade Estadual Paulista, SP

WERKHOFF, P. et al. Vacuum headspace method in aroma research: flavor chemistry of yellow passion fruits. Journal of Agricultural and Food Chemistry, v.46, n.3, p.10761093, 1998. Disponível em: <http://pubs.acs.org/doi/abs/ 10.1021/jf970655s>. Acesso em: 08 jul. 2011. doi: 10.1021/ jf970655s. 